\title{
REVOLUÇÃO INDUSTRIAL E MUDANÇA TECNOLÓGICA NA AGRICULTURA EUROPÉIA
}

\author{
Ademar Ribeiro Romeiro*
}

RESUMO: Este texto aborda questões relativas às transferências nas práticas agrícolas ocorridas na Europa dos séculos XVIII e XIX. Enfocando especialmente a Inglaterra, o autor aborda questốes relativas à distribuição demográfica entre a cidade e o campo.

A colocação de novos instrumentos e a falta de fertilizantes sâo aspectos analisados neste traba1ho. A coerência das transformações é considerada em paralelo à Revolução Inđustrial.
\end{abstract}

As mudanças ocorridas nas práticas agrícolas nos séculos XVIII e XIX na Europa, configurando o que foi chamado por muitos de $1^{\mathrm{a}}$ Revolução Agrícola, estão intimamente ligadas com os fatores que deram origem à Revolução Industrial. Trata-se do aperfeiçoamento e generalização de um sistema de cultura conhecido há muito tempo mas que, por uma série de razões que iremos examinar, teve sua difusão bloqueada por séculos. A grande novidade deste novo sistema de cultura em relação ao sistema em uso consiste na ausência de "pousio". O "pousio" era um método econômico de controle de ervas daninhas e de preparação do solo para o cultivo de cereais. A parcela de terra que antes ficava em "pousio" para ser trabalhada será agora cultivada com espécies vegetais cujas características biológicas (morfologia, tipo de enraizamento, etc.) e os tipos de cuidados que necessitam cumprem as mesmas funções de preparo do solo. Estas novas culturas deverão, por conseguinte, deixar o solo em estado de receber uma cultura de cereal.

As novas espécies de plantas utilizadas são raízes (beterraba, nabo, etc.) e tubérculos (batata, depois da descoberta da América), plantas industriais, (têxteis e tintoriais) e diversas variedades de leguminosas. Os dois primeiros grupos de plantas exigem, além de solos muito bem preparados, um trabalho contínuo de capina até quase a colheita, deixando a terra em ótimo

* Professor do Departamento de Economia da UFF/RJ. 
ROMEIRO, Ademar Ribeiro. Revoluçâo industrial e mudança tecnológica na agricultura européia.

estado para a cultura seguinte. O último grupo é menos exigente do que os primeiros no que concerne ao nível de preparo do solo, mas tem a propriedade de se compor de plantas, as leguminosas, cuja forma de vegetação impede a invasão do terreno por ervas daninhas, além de enriquecer o solo com o nitrogênio atmosférico fixado por bactérias em simbiose com suas raízes.

O cultivo de leguminosas já era largamente difundido há muito tempo ${ }^{1}$. White (1962) vai mais além, dizendo que seu cultivo associado ao de cereais na Idade Média contribuiu de modo decisivo para o desenvolvimento das atividades urbanas e manufatureiras, ao aumentar não só a quantidade de alimentos disponível como também, e principalmente, sua qualidade pela combinação favorável que propiciavam entre hidrocarbonetos e proteínas. As leguminosas eram geralmente cultivadas como cultura de primavera e, de tempos em tempos, na parcela em "pousio" (chamado de pousio "disfarça$\left.\mathrm{do}^{\prime \prime}\right)^{2}$. No entanto, a cultura de leguminosas nāo é suficiente para eliminar completamente a necessidade de trabalhar o solo durante o período de "pousio", que continua indispensável como meio de controle de ervas daninhas e preparação do terreno para o cultivo de cereais. Para tanto, é necessário introduzir o cultivo de raízes e tubérculos na rotação. Vejamos mais detalhadamente as características técnicas do novo sistema.

\section{As características técnicas do novo sistema de rotação de cultura}

Este novo sistema de cultura que vai difundir-se por toda a Europa somente a partir do século XVIII, é notável sob muitos aspectos. Trata-se de um sistema altamente equilibrado do ponto de vista ecológico e ao mesmo tempo altamente produtivo, onde as complementaridades e simbioses naturais entre as diversas espécies animais e vegetais são manejadas inteligentemente. Para substituir o "pousio" como método de controle de ervas daninhas e preparo de solo, este novo sistema segue certas regras agronômicas para estabelecer a posição de cada cultura no esquema de rotação. O princípio de

1 Ver Olivier de Serres (1600, p. 111)

2 Virgílio em suas "Georgicas" livro 1 já recomendava este tipo de prática; "Deixai em seguich se repousarem vossos campos colhidos, e a terra se recuperará em um ano; esperai pelo menos uma estaçẫo antes de semear o trigo e nâo sem antes ter colhido nesta terra uma colheita de ervilhas, de lentilhas, de lupins, frágil e aberta floresta cle legumes ressonando em suas cápsulas trêmulas"... Citado por Zolla, D. (1913, p. 26). 
base é não plantar uma mesma espécie vegetal ${ }^{3}$, sobretudo cereais, seguidas vezes no mesmo terreno de modo a evitar doenças, a infestação mais intensa de ervas daninhas e a degradação da estrutura do solo.

A primeira regra é começar a rotação com uma planta exigente em controle de ervas daninhas e preparo do solo e capaz de suportar uma carga de fertilizantes elevada. As razões desta regra são as seguintes: em primeiro lugar porque, como já mencionamos, as capinas constantes durante quase todo o período de vegetação deixam a terrá bem limpa de ervas daninhas para a cultura seguinte; em segundo lugar porque a possibilidade de concentrar a fertilização numa única parcela de cada vez, reduz o custo de colocação de fertilizantes, bem como o custo de controle de ervas daninhas, pois boa parte da infestação destas é provocada por suas sementes contidas no esterco; por último, está o fato de que para a cultura de cereal que irá ser cultivada em seguida, é importante que ofertilizante orgânico já tenha sofrido um primeiro processo de degradação biológicá.

A segunda regra recomenda semear uma cultura exigente (cereais, principalmente o trigo) quanto ao preparo e ao nível de fertilidade do solo, de modo a aproveitar o bom estado deste deixado pela cultura anterior. A terceira regra indica o cultivo, em seguida, de uma leguminosa de modo a controlar as ervas daninhas que já começam a rebrotar e a melhorar a fertilidade do solo, quase esgotada pela cultura de cereal através da fixação de nitrogênio atmosférico. Finalmente, como quarta e última regra se deve introduzir na rotação uma cultura de cereais menos exigentes que o trigo (aveia ou cevada) para aproveitar a recuperação parcial do solo proporcionada pelo cultivo de leguminosas ${ }^{4}$.

A comparação deste novo sistema de rotação com o sistema trienal medieval com "pousio" nos dá o seguinte quadro: em primeiro lugar, a superfície consagrada ao cultivo de cereais se reduz de $2 / 3$ para $1 / 2$ da área total, que passa a ser dividida em quatro partes iguais, das quais duas recebem forrageiras; em segundo lugar, o cullivo de forrageiras com alto teor de carbohidratos (raízes e tubérculos) e de proteínas (leguminosas) em lugar do "pousio" da terra aumenta enormemente a quantidade e a qualidade do gado que pode ser criado e, em conseqüência, a produção de fertilizantes mada de restibilis, uma palavra que, segundo lteuzé (1862), deu origem à palavra Irancesa $r$ 'trouble' (que significa nova perlubaçâo).

4 Para uma descriçâo completa das regras do novo sistema de culıura no apogeu de sua difusâo no continente europeu ver Domsbale, C. J-A (184.5, p. 5.30-531). 
ROMEIRO, Ademar Ribeiro. Revoluçẫo industrial e mudança tecnológica na agricultura européia.

orgânicos. Timmer (1969) estima a capacidade do novo sistema em 100 unidades/animal ${ }^{5}$ por ano; com o antigo sistema só era possível sustentar 66,6 unidades/animal por ano, sendo 80 durante 8 meses e 40 durante 4 meses de frio, o que impunha a necessidade de se desfazer, via de regra com prejuízo, dos animais antes do inverno. Considerando uma produção média de esterco de 36 "cargas" por unidade/animal por ano, temos uma produção total de fertilizantes orgânicos de 3.600 cargas com o novo sistema, o que representa um aumento de cerca de $50 \%$ relativamente à produção $(2.400)$ obtida anteriormente ${ }^{6}$.

Em terceiro lugar, no que concerne a outras formas de mobilização de nutrientes, o sistema antigo aparentemente tinha a vantagem de dispor dos recursos mais variados contidos nas matas e campos circundantes, enquanto o novo sistema pode dispor apenas do nitrogênio atmosférico fixado por bactérias. Trata-se de uma vantagem aparente porque, como vimos, as perdas no processo de transferência destes nutrientes eram elevadas, especialmente de nitrogênio, um macronutriente essencial. Por outro lado, não se limita ao nitrogênio a capacidade de mobilização de nutrientes do novo sistema; a aplicação sistemática de grandes quantidades de fertilizantes orgânicos aumenta enormemente a atividade biológica dentro do solo, elevando seu potencial enzimático e, em conseqüência, sua capacidade de mobilização interna de nutrientes. Além disso, a melhora considerável da estrutura física da terra que disto resulta, facilita a nutrição vegetal e o armazenamento de água.

\subsection{Rendimento da terra e produtividade do trabalho}

Timmer (1969), havia estimado o aumento do rendimento da terra sob o novo sistema em cerca de $10 \%$ para os cereais e $50 \%$ para os produtos animais; no caso dos cereais trata-se de um aumento muito modesto, que não compensa a redução da área $(21 \%)$ cultivada com cereais. Desse modo, o aumento global do rendimento da terra seria, no máximo, próximo do aumen-

5 A unichde/animal é definida em termos das necessidades alimentares e capacidade cle produçâo de esterco cle cada tipo de animal. As equivalências entre as espécies animais são as seguintes: 1 cavalo $=2$ bois $=10$ carneiros.

6 Estes dados estão subestimados na medich em que Timmer nâo considera as diferenças na produção de esterco por unidade/animal decorrente da melhor alimentaçâo do gado no novo sistema. 
to da quantidade de trabalho exigido pelas novas práticas agrícolas, estimado em $45 \%$ (33,7 homens/ano contra $23,2 \%$ no antigo sistema). Estas estimativas confortam, evidentemente, as teses de autores como Boserup (1967), para quem as novas técnicas de menor produtividade do trabalho só foram introduzidas porque não havia outro meio de prover o sustento de uma população crescente.

No entanto, existem elementos suficientes para pôr em dúvida estas estimativas. Em primeiro lugar, no que concerne aos rendimentos da terra, Timmer não leva em devida conta o fato de que a maior disponibilidade de fertilizantes no novo sistema vai dar início a um processo de acumulação progressiva $^{7}$ de fertilidade o qual, segundo Mazoyer (1977), resultará na multiplicação por dois da produção por hectare de plantas e de produtos animais (aliás, este novo sistema de cultura também era conhecido pelo nome de cultura progressiva ou melhoradora).

Em segundo lugar, do ponto de vis ta da produtividade do trabalho, o aumento das necessidades de mão-de-obra não será suficientemente elevado para anular o aumento dos rendimentos da terra. O trabalho necessário será assim redistribuído; os trabalhos antes executados na parcela de terra em "pousio" (1/3 da área total) são substituídos pelos trabalhos de preparo e de controle de ervas daninhas para o cultivo de plantas forrageiras que ocupam $1 / 2$ da área total. Como foi visto, um dos tipos de culturas forrageiras utilizados, as leguminosas, não exige trabalho de capina; assim, sobre 1/4 da área cultivada o trabalho de preparo do campo é bem menor do que aquele executado na terra em "pousio". A carga maior do trabalho fica concentrada nos outros $25 \%$ da superfície consagrados ao cultivo das forrageiras que servem de abertura do processo de rotação (raízes e tubérculos). Como vimos, é nesta faixa onde se procura concentrar a maior parte do esforço com o objetivo, além das exigências específicas destes tipos de plantas, de poupar trabalho através de ganhos de escala.

De modo esquemático o quadro abaixo ilustra as diferenças entre os dois sistemas, permitindo visualizar melhor as respectivas distribuições da carga de trabalho ao longo do calendário agrícola. No novo sistema temos a seguinte distribuição: trabalhos intensos de preparação do campo, de espalhamento de fertilizantes e de controle de ervas daninhas para o cultivo da

7 Nas palavras de Lecouteux (1881, p. 81): "Deve haver no solo fertilizantes capitalizados a longo prazo, isto é, um fundo de fertilização quase imobiliário, juntamente com fertilizantes que constituem um capital essencialmente circulante, um capital essencialmente mobiliário". 
ROMEIRO, Ademar Ribeiro. Revoluçẩo inclustrial e mudança tecnológica na agricultura européia.

cultura de abertura da rotação; trabahtho ligeiro de preparação do solo para o cultivo do cereal que se segue à cultura de abertura; trabalho ligeiro de preparo da terra para a cultura da forrageira seguinte (leguminosas); e, finalmente, trabalho de preparação do solo para a cultura do cereal que fecha a rotação. No antigo sistema: trabalhos intensos de preparação do solo e espalhamento de fertilizantes sobre a parcela em "pousio"; trabalho leve de preparo do campo para a cultura do cereal de inverno; trabalho rápido de preparo do solo para a cultura de primavera que fecha a rotação.

Comparação entre os dois sistemas:

$\begin{array}{clc}\begin{array}{c}\text { Sistema antigo } \\ \text { (hectares) } \\ 120\end{array} & \text { Culturas } & \begin{array}{c}\text { Sistema novo } \\ \text { (hectares) }\end{array} \\ 120 & \text { Trigo } & 120 \\ 120 & \text { Centeio } & 120 \\ 0 & \text { "Pousio" } & 0 \\ 0 & \text { Nabo } & 120 \\ 140 & \text { Trevo } & 120 \\ 500 & \text { Campo } & 20 \\ & \text { Total } & 500\end{array}$

fonte: Timmer, P.C. (1969)

Considerando-se o grau de intensidade do trabalho, temos a seguinte distribuição deste sobre a área total dos dois sistemas: no sistema de rotação trienal o trabalho pesado se realiza sobre $1 / 3$ da área total e o trabalho leve sobre os $2 / 3$ restantes; no sistema de rolação de tipo Norfolk temos respectivamente $1 / 4$ e $3 / 4$. O trabalho realizado na cultura de abertura deste último exige efetivamente um contingente maior de mâo-de-obra, enquanto as capinas forem manuais. No entanto, de modo algum se pode afirmar que isto anula o aumento do rendimento da terra obtido implicando, por conseguinte, a queda da produtividade do trabalho. Menos ainda depois da invenção por Jethro Tull da sementeira e da carpideira mecânicas puxadas por cavalo no início do século XVIII. A invenção da carpideira mecânica vai reduzir a tal ponto o custo das capinas que Duhamel du Monceau (1753), o divulgador dos métodos de Tull na França, estimá que se tornara viável abandonar o "pousio" para praticar a monocultura do trigo ("o mais precioso de todos os grãos") em toda a superfície cultivada. 
Para fazê-lo Duhamel du Monceau recomenda a utilização do semeador mecânico para semear o trigo em linhas bem separadas uma das outras de modo a permitir a passagem da carpideira mecânica: "...seguindo o costume, um terço das terras permanecem todo ano sem nada produzir; outro terço é cultivado com grãos menos preciosos que o trigo; desse modo, apenas um terço das terras de uma fazenda é destinada à produção do trigo. Seguindo o novo método, todas as terras podem ser cultivadas com trigo; no entanto, devido ao espaçamento que se faz necessário entre as linhas de sementes, na prática, apenas um terço do espaço é aproveitado. Resta saber se as linhas de trigo crescem com suficiente vigor, produzindo o suficiente de trigo para compensar, não apenas o abandono da cultura da aveia (estimada em um terço da colheita do trigo), mas ainda para aumentar o lucro do Lavrador"... Duhamel du Monceau; H.L. (1753, p. 284, tomo 1).

Em outras palavras, a monocultura do trigo seria viável se, tendo em conta o preço do trigo e o custo da capina contínua (suposto não superior ao do método de "pousio"), o aumento do rendimento da terra fosse suficiente para compensar o abandono das demais culturas de cereais. Duhamel du Monceau acreditava que sim, pois no novo método de $\mathrm{Tull}^{8}$ o papel da carpideira mecânica não se limitava a controlar ervas daninhas, mas também revolver o solo o mais intensamente possível durante todo o período de crescimento das plantas, para facilitar sua nutrição na crença de que estas se nutriam de partículas de solo (a concepção aristotélica de nutrição).

Além da introdução destes novos tipos de instrumentos, é preciso considerar tamberm as melhorias realizadas nos equipamentos existentes. Heuzé (1862) observava, na segunda metade do século XIX, que as melhorias realizadas no arado haviam diminuido significativamente o custo dos trabalhos de preparação do solo, através de uma redução de 3 para 20 número de cavalos necessários para tracioná-lo por cada 40 hectares ${ }^{9}$. Em resumo, o novo sistema de cultura exige no início uma maior quantidade de mão-de-

8 Para Tull o trabalho de solo cumpria o mesmo papel do fertilizante, cujo papel se limitava a dividir o solo através da fermentação: "Tillage is breaking and dividing the Ground by Spade, Plow, Houe, or other Instruments, which divide by a sort of Attrition (or Contusion) as Dung does by Fermentation". Tull, J. (1753, p. 27).

9 Este foi o caso do famoso arado triangular de Roherdam. Demolon (1946) assinala que apos a invençấo do dynamômetro, que permite medir o grau de resistência à traçấo oposta pelos diversos instrumentos, a resistência à tração do arado por $\mathrm{cm}^{2}$ de terra trabalhada diminuiu de 3 para 1 durante o século XIX. A grade patenteada por Amstrong em 1839, cujo desenho eliminava os movimentos laterais que reduziam sua eficiência, foi o protótipo das grades modernas. Ver Beaumont, O. and Higgs J.W.Y. (1958). 
ROMEIRO, Ademar Ribeiro. Revolução industrial e mudança tecnológica na agricultura européia.

obra do que o sistema anterior, embora sem queda da produtividade do trabalho. Em seguida, a acumulação progressiva da fertilidade do solo conduz a uma duplicação dos rendimentos, ao mesmo tempo em que a introdução de novos instrumentos e o aperfeiçoamento dos antigos reduzem substancialmente a quantidade de mão-de-obra necessária. Este novo sistema de cultura, em seu apogeu na Inglaterra no século XVIII e no Continente no século XIX, tornava possível alimentar uma população camponesa crescente e ao mesmo tempo uma população equivalente nas cidades ${ }^{10}$.

Cabe observar, no entanto, que este sistema de cultura continua relativamente intenso em trabalho durante a Revolução Industrial na Inglaterra, o que contradiz a análise de Marx sobre sua difusão como causa do êxodo rural, como já haviam notado Landes (1969) e outros autores. A mão-de-obra liberada pelo movimento de cercamento de terras ("enclousures") a que se refere Marx será absorvida em grande parte pelo novo sistema de cultura. A liberação significativa de trabalho pelo novo sistema só ocorre após a consolidação da revolução industrial. Marx confunde dois movimentos de cercamentos de terra distintos. O movimento de cercamento que efetivamente expulsou mão-de-obra rural ocorreu nos séculos XVI e XVII e tinha por objetivo a criação de ovelhas para produzir lã de exportação.

Braudel (1979, tomo 3) nos explica que não foram as populações estritamente agrícolas que forneceram a mão-de-obra barata para a Revolução Industrial, mas sim aquelas populações de regiões pobres de agricultura decadente. Segundo ele, as novas culturas forrageiras que caracterizam o novo sistema de cultura, exigem solos leves (arenosos), o que transforma as regióes que os contém em terras ricas da Inglaterra. Por outro lado, as regióes de solos pesados (argilosos), até então consideradas as melhores terras para o cultivo de cereais, pouco adaptáveis às culturas de forrageiras ${ }^{11}$, são

10 Esta estimativa é compatível com os dados sobre a população urbana dos principais países rurais. De acordo com Dovring (1965), a população urbana na Inglaterra no final do século XVIII já era superior à população rural. Nos demais países do continente (Europa Ocidental) isto vai acontecer somente no final do século XIX.

11 Não é totalmente correto dizer que as terras mais pesadas sejam pouco adaptáveis à cultura de forrageiras. O que se passa é que a cultura de forrageiras (raízes e tubérculos) exige um preparo mais intensivo do solo e melhores condições de drenagem o que é mais fácil de se obter, tendo em conta os equipamentos disponíveis no século XVIII, nos solos leves. Fussell (1958, p. 22) enfatiza particularmente os problemas de drenagem colocados pelos solos argilosos pesados, os quais só foram definitivamente solucionados no século XIX com a invençâo dos tubos de drenagem e de um equipamento para a colocaçâo mecanizada destes (o arado de drenagem de Fowler). 
condenados pela baixa do preço do trigo provocada pelos altos rendimentos obtidos com o novo sistema nas regiões de solos leves. Estas regiões que se tornam desfavorecidas vão procurar se reequilibrar sobretudo através da indústria artesanal rural, aproveitando o movimento de "putting out". A partir do momento que a manufatura capitalista urbana se afirma (final do século XVIII) este artesanato será destruído, liberando a mão-de-obra, composta de pequenos artesãos e de um proletariado mais ou menos habituado às atividades artesanais, que irá se constituir no "exército industrial de reserva", à disposição do capital.

\section{A dinâmica da mudança técnica}

Na Idade Média o progresso técnico, sobretudo nas práticas agrícolas (a passagem do sistema bienal para o trienal), havia aumentado significativamente o nível de acumulação de capital da economia. O desenvolvimento de atividades urbanas, artesanais e comerciais havia se intensificado, enfraquecendo progressivamente as relações de servidão. Na França estas tendências de desagregação do feudalismo já se faziam sentir desde os séculos XI e XII, bem antes da Inglaterra e da Alemanha, através da diminuição progressiva das corvéias e da redução do tamanho dos feudos em benefício de camponeses livres (parcelários); o senhor feudal se transforma pouco a pouco em rentier do solo ${ }^{12}$. No entanto, no século XIV as fomes freqüentes, como a crise do trigo e as fomes de 1315-1317, indicavam os limites do antigo sistema agrário diante da crescente urbanização e pressão demográfica ${ }^{13}$.

Aparentemente existiam todas as pré-condições para a introdução de um novo sistema de cultura. Do lado da demanda havia não apenas a fome da população camponesa, mas também um mercado urbano em rápida expansão para produtos animais mais nobres e matérias primas para a produção artesanal (plantas têxteis e tintoriais) cuja produção, como vimos, fazia parte do

12 Segundo Bloch (1976), se por hipótese a revolução francesa tivesse ocorrido em 1480 e nâo em 1789, ela teria deixaclo a terra a uma multidăo de pequenos ocupantes.

13 Entre os séculos XI e XIV houve uma forte expansão demográfica, que praticamente esgotou a fronteira agrícola. Foi uma época de grandes derrubadas de matas e drenagem de grandes regiốes pnntanosas, empreendimentos onde os grandes mosteiros tiveram um papel de ponta. Ver Ganshof, F.L. (1942). Le Roy Ladurie (1977) calcula para a França uma população de 17 milhōes na primeira metade do século XIV, quase tâo grande quanto a populaçăo francesa no iń́cio do século XVIII. 
ROMEIRO, Ademar Ribeiro. Revoluçâo industrial e muđança tecnológica na agricultura europeia.

novo sistema de rotação de culturas. Do lado da oferta, a mão-de-obra disponível era suficiente e a desagregação das instituições feudais tornava possível suprimir os direitos de uso comunitário dos recursos fundiários de modo a permitir a instalação do novo sistema. E de fato o novo sistema foi introduzido, desde os séculos XII e XIII, primeiro no norte da Itália (Lombardia) ${ }^{14}$ e depois nos Países Baixos (Flandres), regiões que melhor reuniam estas pré-condições. No entanto, sua difusão para o restante da Europa só vai ocorrer séculos depois, processo que ficou conhecido por "Revolução Agrícola" dos séculos XVIII e XIX ${ }^{15}$.

\subsection{Demografia e regressão econômica}

A enorme expansão da Europa entre os séculos XI e XIII se desaba com a fabulosa recessão dos séculos XIV e XV seguintes. Em 1350 a peste negra devasta o estreito Continente. Mas ela não foi o único fator que enterrou a precedente expansão. Uma lenta, mas possante desaceleração já havia começado muito antes, no final do século XIII. De acordo com numerosos estudos, não seria possível explicar a enorme amplitude das devastações provocadas pela peste negra, sem considerar o estado de baixa resistência física em que se encontravam as populações devido à crônica falta de alimentos ${ }^{16}$. A agricultura se mostrava incapaz de aumentar a produção, através da introdução de novos métodos, no ritmo necessário para acompanhar o crescimento demográfico e urbano.

Esta é a hipótese de Braudel (1979, tomo 3, p. 473): "Como explicar, então, a maior vitória e a maior derrota que a Europa conheceu antes do século XVIII inglês? Muito provavelmente pela amplitude de um crescimen-

14 Segundo Heuzé (1862) desde o Império Romano este sistema de cultura já era praticado em algumas regiôes do norte da Itália, só que em rotaçôes alternadas de 3 culturas: nabos/trigo/favas e nabos/trigo/cevach. Ver Heuze, G. (1862, p. 6-10).

15 A palavra "revoluçăo" utilizada corretamente quanclo se fala da difusão do sistema de rotaçấo de culturas do tipo Norfolk nos séculos XVIII e XIX é contestada por alguns historiadores, que preferem falar de uma aceleração na difusâo do progresso técnico. Este é o crsso notadamente de Slicher van Bath, B. H. (1969) e de Mingay, G. E. (1977).

16 Hobsbawn (1975) faz um balanço das pesquisas recentes que procuram mostrar que a amplitude dos estragos causados pelas epidemias de peste bulbônica nâo poderia ser explicada sem estar associada à fome. Parece haver indícios de que a virulência da peste esteja também associada a uma mutação sofrida pelo agente patógeno, o que tornou mais frágeis ainda as defesas do sistema imunológico destas populaçũes. 
to demográfico que a produção agrícola não acompanhou a partir de certo ponto. Os rendimentos decrescentes são a sina de toda agricultura empurrada para além de seus limites, quando the faltam os métodos e técnicas capazes de sustar o desgaste rápido dos solos". A pergunta a fazer agora é por que finalmente esta pressão demográfica não foi suficiente para estimular a introdução de novas técnicas.

Para responder a esta questão é preciso considerar separadamente a reação das duas categorias de agentes produtivos existentes: a grande massa camponesa e os agricultores capitalistas (kulaks ou Yeomen). A grande massa camponesa, na medida em que a fronteira agrícola se esgotava, ia estendendo pouco a pouco os campos de cultura em direção aos bosques e campos naturais circundantes. Desse modo, a capacidade de manutenção da fertilidade do sistema ia se reduzindo também progressivamente. Para compensar a queda nos rendimentos os camponeses intensificavam os trabalhos de preparo de solo e controle de ervas daninhas de modo a tirar o máximo da terra (o arado era substituído pela enxada), mas não mudavam de sistema de cultura. E não era por desconhecimento porque, como vimos, o novo sistema de rotação já era conhecido desde longa data.

Como pondera Laurent (1976, p. 665), para os camponeses, o aumento das bocas a alimentar significava antes de tudo aumentar a produção de cereais para fazer o pão, que se tornara, mais do que nunca, o alimento de base à medida em que a caça se escasseara. No novo sistema, como vimos, a superfície consagrada aos cereais se reduzia de $2 / 3$ para $1 / 2$ da superfície total. Era necessário esperar alguns anos para que a melhoria progressiva da fertilidade da terra sob o novo sistema compensasse esta redução da área cultivada com cereais. Este fato reforça, portanto, a inércia "natural" que incita os agricultores a se manterem segundo a experiência dos antigos. Este tipo de resistência à mudança nos métodos de cultura estará presente ainda em pleno século XIX, quando a generalizaçâo das novas práticas se torna irreversível.

Fatores naturais e político-institucionais tenderam a agravar esta inércia que dificultava a introdução de novos métodos de cultura. No que concerne aos fatores naturais, trata-se do movimento cíclico glacial secular. Depois de ter se expandido entre os séculos V e VIII, o movimento glacial havia entrado numa fase decrescente, tornando o clima mais ameno e favorável à agricultura. No entanto, como mostra Duby (1973), este movimento se inverte bruscamente na metade do século XII iniciando um período, que termina um século depois, extremamente frio e chuvoso, aumentando significativamente os riscos de perdas. Quanto aos fatores político-institucionais, a degra- 
ROMEIRO, Ademar Ribeiro. Revoluçẩo industrial e mudança tecnológica na agricultura européia.

dação das instituições feudais não somente reduziu o grau de proteção social assegurado pelo costume (acesso aos recursos comunitários, carga tributária constante, etc.), como também expôs a massa camponesa a atos de pilhagem cometidos em guerras não mais reguladas pelos códigos feudais de honra e civilidade ${ }^{17}$.

North e Thomas (1973) dão ênfase a estes fatores políticos e institucionais para explicar a incapacidade de inovar do campesinato diante da pressão demográfica. Esta desagregação das instituições feudais havia provocado uma reação da classe senhorial para recuperar os privilégios perdidos. Esta reação da classe senhorial (fato que iremos examinar com mais detalhe na próxima seção) se faz num contexto de escassez de terras e excesso de mão-de-obra que a favorece. Esta mudança radical na disponibilidade relativa de fatores de produção favoreceria, portanto, uma revisão dos contratos de trabalho fixados no passado em função de uma outra grade de preços relativos.

Apesar de tudo, com o aumento progressivo da sobrecarga de trabalho e a degradação das condições de vida se poderia supor que, ao menos em tese, desapareceriam as hesitações engendradas pelos riscos que poderiam advir com uma mudança de sistema de cultura, especialmente diante da certeza da fome. Tal não é o caso. Paradoxalmente a pressão demográfica se constitui num entrave à mudança técnica. Como observa Braudel (1979, tomo 2, p.220), "uma população camponesa tão numerosa, próxima de uma economia de subsistência, obrigada a trabalhar sem tréguas para suportar os contragolpes das freqüentes quebras de colheitas e pagar os múltiplos impostos, se fecha nas suas tarefas e preocupações cotidianas. Como que paralisada diante de qualquer movimento novo. Não é neste meio que se pode imaginar a propagação fácil do progresso técnico ou a aceitação do risco de novas culturas e de novos mercados".

Com relação aos agricultores capitalistas (kulaks), por definição mais receptivos a inovações tecnológicas que aumentam a rentabilidade do sistema produtivo, nós vimos que estes haviam difundido o novo sistema de cultura no norte da Itália e na Flandres. Estas regiões representavam a vanguarda do capitalismo nascente, com elevado grau de urbanização e intensas atividades manufatureiras e comerciais. Conseqüentemente, havia

17 Durante a guerra dos cem anos, a primeira entre dois Estados nacionais em formaçâo, todos estes códigos foram desrespeitados: assassinatos de prisioneiros, destruição de lavouras, saques e pilhagens contra aldeias camponesas etc. 
um mercado suficientemente grande para novos produtos agrícolas, sobretudo de matérias primas para o setor manufatureiro, o que tornava o novo sistema de cultura um investimento rentável. No restante do Continente, no entanto, a progressiva definição de grandes espaços nacionais se fazia sobre uma base econômica ainda pulverizada e frágil, tornando inviável o investimento no novo sistema, investimento este de longo período de maturação e de gastos elevados em instalações e animais.

\subsubsection{Crise e mudança institucional}

A desagregação progressiva do feudalismo não deixou indiferente a classe de senhores feudais. Apesar das perdas sofridas, restava ao senhor feudal trunfos importantes. O senhor não é apenas um rentier, mas também um grande proprietário de terras das quais ele pode dispor como quiser. Ele possui uma grande parte das florestas e campos naturais que restam, cuja exploração pelos camponeses só será permitida mediante pagamento de um imposto ("champart"); ele tem o direito de prioridade na compra de toda terra colocada à venda ("retrait feudal"). Ele tem o direito também de cobrar uma taxa sobre os mercados, feiras e pedágios que se encontrem em suas terras. A própria liberdade que o servo havia pouco a pouco conquistado é bem relativa; ele é livre sim, mas ele deve servir, cultivar a terra, a qual continua sob o controle do senhor ${ }^{18}$. Assim, a sociedade senhorial apesar de sacudida, atingida, minada, vai se recompor durante o período de recuperação econômica e demográfica dos séculos XV e XVI e tentar recuperar o espaço perdido ${ }^{19}$.

No entanto, esta recuperação não teria sido possível sem uma nova ordem institucional representada pelo absolutismo, especialmente tendo em conta que a fabulosa regressão demográfica provocada pela peste havia tornado a mão-de-obra escassa, o que tendia a favorecer o camponês. Assim, esta sociedade desestruturada procura e encontra um novo equilíbrio na instalação de um Estado territorial. Segundo Takahashi (1972) e vários

18 Como recitava um pregador austríaco em 1676, fazendo o elogio do seu tempo: "Deus seja louvado, agora năo existem mais servos nas redondezas, cada um hoje em dia pode e deve servir onde quiser", citado por Braudel, F. (1979, tomo 2, p. 225-229).

19 Na França, entre 1480 e 1789 a grande propriedade havia se reconstituido, embora em menor grau que na Alemanha e Inglaterra. Ver Bloch, M. (1976). 
ROMEIRO, Ademar Ribeiro. Revolução industrial e mudança tecnológica na agricultura européia.

outros historiadores, o absolutismo deve ser considerado como parte do movimento geral de reação da classe senhorial contra as tendências de desagregação do feudalismo. Doravante a autoridade do senhor de terras dependerá do poder real, que lhe garantirá a recuperaçáo dos antigos direitos feudais (e outros que serão criados) de cobrança de rendas fundiárias, sem a contrapartida dos deveres tradicionais para com os camponeses.

Este novo contexto institucional apresenta ao mesmo tempo fatores de estímulo e de retardamento à expansão das relações de produção capitalistas. O fator de estímulo fundamental decorre da unificação dos mercados nacionais como consequêencia da unificação política. Como fator de atraso principal está, no plano cultural, a predominância de ideais de nobreza pseudofeudais e seu efeito sobre a difusăo da mentalidade empresarial. Assim, por exemplo, a exploraçăo das terras compradas por comerciantes das cidades tende a ser feita através de uma combinação eficaz de renda feudal e usura; ou então a compra de terra decorre do desejo de ascender ao status feudal de nobreza. Como observa Braudel (1979, tomo 2), qualquer que seja sua origem, estas propriedades urbanas não são capitalistas. Podem até ser geridas segundo os bons princípios contábeis, mas sua estrutura não se modifica. Elas continuam como senhorias, com seus velhos direitos e servos.

Como resultado, se desenvolve uma burguesia que não é empreendedora da terra, mas que vive sobre as costas de um campesinato cada vez mais explorado por ela e pelas demandas do Estado. É claro que existem muitas excessões a esta regra. A expansão do comércio e da manufatura, da mesma forma que anteriormente no apogeu do feudalismo, estimula o surgimento de capitalistas rurais que introduzem inovações visando a produção dos novos produtos exigidos pelo mercado em expansão.

\subsection{O papel do Mercado}

De modo geral, até o século XVIII as novas práticas agrícolas ficaram circunscritas no norte da Itália, onde aparece o primeiro manual de rotação de culturas $^{20}$, e na Flandres, enquanto no restante da Europa a reação senhorial se afirmava. A expansão econômica do século XVI não foi suficientemente forte de modo a ameaçar o quadro social desenhado por esta reação.

Ricordo dAgricoltura, de Camillo Torello, publicado em Mântova em 1577. 
O possante desenvolvimento comercial, manufatureiro e agrícola, nestas duas regiões, acaba por se arrefecer sem desembocar numa revolução industrial. Aparentemente todas as pré-condições para isto estavam presentes. A propósito da Lombardia, Braudel (1979, tomo 3) observa que nem as fontes de energia existentes, nem o nível tecnológico poderiam explicar este fato. A revolução industrial na Inglaterra não dependeu de um progresso científico e tecnológico que já não estivesse ao alcance da mảo no século XVI. Trata-se de um fato que tem provocado contínuas controvérsias entre os historiadores na medida em que os dados existentes não fornecem provas decisivas. Só existem conjecturas.

Para Braudel, é novamente o obstáculo representado pela estreiteza do mercado, a causa principal da não introdução dos novos métodos produtivos, no caso, industriais. No norte da Itália o tamanho do mercado tinha sido suficientemente grande para estimular a introdução das novas práticas agrícolas, mas não suficiente para dar lugar a uma revolução industrial. $O$ problema residia nas características do tipo de comércio praticado. Como nota Hobsbawn (1975, p. 89), para que ocorra a revolução técnica e social que caracteriza o capitalismo é necessário que haja uma produção de massa e não uma produção de luxo destinada a proporcionar o maior lucro possível por unidade vendida. No século XVI monopolizar o comércio de especiarias ou de produtos de luxo era mais atrativo do que investir na produção de produtos populares. A reação da classe senhorial havia bloqueado, como vimos, o desenvolvimento de um mercado de produtos de consumo de massa.

A longa prosperidade do século XVI termina com a crise geral do século XVII. Esta expansão econômica havia se processado num quadro institucional e social que the era contraditório. Desse modo, segundo Hobsbawn (1975), as múltiplas perturbações ocorridas no século XVII (o declínio do afluxo da prata da América espanhola, o colapso do comércio no mar báltico, entre outras) vão precipitar a crise na medida em que se abatem sobre uma estrutura já profundamente minada por esta contradição. Novamente o aumento da produção de cereais através da expansão da fronteira agrícola que a peste havia recriado encontra seus limites 21 e a fome se multiplica deixando

21 Como observa Le Roy Ladurie (1977, p. 581), "a partir de 1.500 a curva da produção de cereais se torna lenta, mas seguramente assintótica à horizontal indicando, assim, a saturaçấo progressiva das terras disponiveis, que haviam sido abandonadas entre 1348 e 1440 , num sistema onde a produçâo por hectare praticamente não aumenta; e onde os proprietários de florestas, bem como as exigências mínimas de lenha e madeira não permitem a extensăo dos cultivos". 
ROMEIRO, Ademar Ribeiro. Revoluçáo industrial e mudança tecnologica na agricultura européia.

atrás dela um campesinato esgotado e enfraquecido ${ }^{22}$. A expansão das atividades manufatureiras e comerciais nas cidades da Europa Ocidental passara a depender dos excedentes alimentares exportados da Europa Oriental através do mercado do mar Báltico ${ }^{23}$. Ao fim deste período de crise econômica e de agitação social, a empresa capitalista que havia sido forçada a se adaptar a um quadro institucional de caráter ainda feudal (o "putting out system"), vai finalmente se transformar na empresa capitalista transformadora do mundo à sua imagem.

\subsection{A especificidade inglesa}

A Inglaterra, onde esta transformação ocorrerá em primeiro lugar no século XVIII, já havia se tornado na véspera de sua guerra civil (1642) o primeiro país industrial da Europa. Um século antes, as Ilhas Britânicas estavam atrás dos países continentais em matéria de desenvolvimento industrial. A aceleração do crescimento industrial que faz esta situação se inverter já apresentava algumas características específicas quando comparada com o que ocorria no continente: o tamanho das empresas e número de trabalhadores, dos quais uma grande parte sem qualificação ${ }^{24}$, e inovações originais decorrentes das restriçōes técnicas impostas pela necessidade de utilizar o carvão mineral em lugar do carvão vegetal que se torna escasso. Isto explica,

22 Hobsbawn $(1975$, p. 88) assinala que "jamais, descle o século XIV, se registrou tantas doenças durante um século". Por outro lado, como observa Usher (1913, p. 240, 241), o problema da penúria de grăos era agravado pelas más condições de transporte, o que provocava inumeráveis conflitos entre as regiōes produtoras e os centros urbanos consumidores, com a vantagem para estes últimos cujo poder de barganha era superior.

23 A obtenção de excedentes alimentares adicionais sem mudar de sistema de cultura foi feita atraves de um aumento da taxa de exploração do campesinato, que se traduziu na retomada das relações de servidăo (fenômeno que ficou conhecido como a segunda servidăo na Europn Oriental). Braudel (1979, tomo 2, p. 232) nota que a corvéia passa de um dia por semana no inf́cio do século XVI para seis dias por semana um século depois. Diante da perspectiva de renda oferecida pelos mercados ocidentais os senhores de terras văo, além de explorar ao limite da sobrevivência os camponeses, ser tentados a avançar os cultivos sobre as florestas e campos naturais, comprometendo a produtividade do sistema. Kula (1979, p. 32) observa a este propósito a contradiçăo vivida pelos senhores de terra polonesas entre o desejo de ganhar dinheiro e aquele de evitar a degradaçăo do dominio.

24 Um dos gerentes de uma fábrica de alun em Yorkshire (que empregava regularmente 60 trabalhadores) explica, em 1619, que a fabricação de alun é uma "tarefa de louco" e que nấo pode ser realizada por um só homem nem por uns poucos; "mas por uma multidăo de gente da mais baixa categoria, que năo dedicam nem cuidado, nem lealdade a seu trabalho". Citado por Braudel, F. (1979, tomo 3, p. 478). 
provavelmente, o fato de que a crise geral da economia européia no século XVII tenha atingido menos a economia inglesa.

Da mesma forma que nos demais países europeus, houve também um forte crescimento demográfico ao longo do século XVI, mas com a diferença de que o processo de urbanização foi bem mais acentuado. Este último fato é muito importante para explicar o que nos interessa aqui, a evolução das técnicas agrícolas. A difusão do novo sistema de cultura começa lentamente a partir da segunda metade do século XVI. Inicialmente a agricultura responde à demanda crescente do mesmo modo que no restante da Europa: aumentando a superfície cultivada. Como na França, os limites deste tipo de resposta são atingidos rapidamente, mas ao contrário do que se passou nesta última, onde as crises alimentares se sucedem atingindo duramente os camponeses, aqui, o aumento dos preços agrícolas se traduzem num bem estar evidente nos campos, que se tornam um mercado considerável para as indústrias que se desenvolvem ${ }^{25}$.

Estes fatos indicam que a reação da classe senhorial na Inglaterra não foi da mesma ordem que a ocorrida no continente. De fato, sob o impacto desta expansão industrial e urbana as relações arcaicas entre senhores e camponeses se transformam de modo mais profundo. Para o senhor, a terra continua a ser um instrumento de prestígio social, mas se torna também um instrumento de produção que ele procura confiar a arrendatários eficazes. Um domínio próspero, arrendado por bom preço, apresenta ainda a vantagem de servir como garantia para a captação de crédito fácil para outros investimentos, pois freqüentemente o senhor de terra se torna também um empresário industrial ou mineiro. A principal característica desta nova ordem é a ascensão do arrendatário capitalista, um verdadeiro empresário que tem seu contrato garantido por convenção, podendo legalmente investir sem medo e gerir sua exploração segundo as regras do mercado e da gestão capitalista ${ }^{26}$.

A maior parte destes empresários rurais surge do vigoroso processo de diferenciação social do campesinato, que o divide, de um lado, entre camponeses que possuem um pequeno pedaço de terra e têm direito ainda ao uso

25 É a época do "Great Rebuiling", quando as casas camponesas "sẫo reconstruídas, ampliadas, melhoradas, o segundo andar substitui o celeiro, as janelas são guarnecidas de vidros, os fogões adaptados para o uso de carvẫo mineral; os inventários de morte assinalam esta abundância nova de móveis, roupas, pinturas e vasilhame de estanho". Como nota Braudel (1979, tomo, p. 479), esta demanda certamente estimulou a indústria, o comércio e as importações.

26 Sobre a luta, na Inglaterra, por contratos de arrendamento que permitissem os investimentos necessários para melhorar as práticas agrícolas, ver W. Marshal (Rural Economy of the Midlands Counties, 1790) e J. Caird (English Agriculture in 1850/1851) in Mingay, G.E. (1977). 
ROMEIRO, Ademar Ribeiro. Revolução industrial e mudança tecnológica na agricultura européia.

dos recursos comunais e, de outro, pequenos (às vezes grandes) proprietários independentes, ou yeomen, mais ou menos "condenados" a aumentarem suas possessōes para sobreviver, evitando se tornarem trabalhadores assalariados. Desse modo, as terras tendem a ser reagrupadas pouco a pouco nas mãos seja do grande yeoman, seja do grande arrendatário capitalista, além é claro da nobreza fundiária.

Assim, ao longo do século XVII se reunem, na Inglaterra, as pré-condições para a difusão do novo sistema de rotação de cultura de tipo Norfolk. Ao lado da demanda o desenvolvimento de um mercado urbano/industrial suficientemente vigoroso para produtos animais e plantas industriais; como dizia Lecouteux (1855, p. 91), um apologista dos métodos ingleses na França, "o mais vivo estimulante do progresso agrícola é o mercado, a colocação dos produtos a um preço remunerador". Ele fala com entusiasmo do papel decisivo cumprido pela criação de uma nova raça de carneiros, na melhoria dos métodos de cultivo, uma passagem que merece ser citada por sua clareza:

"Como são estimulantes estes Merinos! que belo problema financeiro eles vêm resolver. Pois enfim, até agora, o velho sistema trienal havia habituado o agricultor a só fazer dinheiro com grãos e, de repente, eis os merinos que vieram lhe provar, dinheiro na mão, que era tão rendoso cultivar forrageiras quanto cultivar cereais, ou ao menos, que seria prova de habilidade partilhar a terra entre estes dois produtos: uns, as forragens, se convertendo, no mesmo ano, em esterco, em lã e dinheiro, - outros, os grãos, conservando seu antigo privilégio de se vender prontamente, mas ganhando a sua aliança com as forragens, a vantagem de produzir mais num espaço menor. O que seria preciso mais para progredir, para melhorar o solo, para enriquecer o arrendatário e o proprietário". Lecouteux, E. (1855, p. 93).

Do lado da oferta está, em primeiro lugar, a ruptura das relações de servidão, condição indispensável. Em seguida, estão os camponeses que têm os meios e a perspectiva favorável para investir. O novo sistema exige investimentos relativamente pesados e a plena maturação não é imediata. $\mathrm{A}$ nova raça de carneiros, pela sua produtividade e qualidade de lã, foi muito importante para reduzir o tempo de espera do retorno do investimento (aumento do rendimento na produção de grãos) ${ }^{27}$. De qualquer modo, é preciso obstáculo ao abandono do sistema de "pousio". No entanto, outros especialistas da época observam que é possível mudar pouco a pouco de sistema de cultura através de modificações parciais. Trata-se do que Lecouteux (1881, p. 47-50) chama de "andar no tempo". "A cultura intensiva ou através do capital, eis o objetivo. A cultura extensiva ou através do tempo, eis, em muitos casos, o meio". 
comprar os animais e construir as instalações para alojá-los. O cultivo de forrageiras, o que exige mais mão-de-obra, elevando o custo em salários. Finalmente, há que se esperar o acúmulo de fertilidade para que o aumento dos rendimentos das culturas de grãos compense a redução da área cultivada. Como observa Lecouteux (1855, p.7), "a cultura progressiva exige 3 coisas da parte do agricultor: tempo, isto é, a possibilidade de esperar pelos resultados; capital, isto é, o meio de proporcionar os avanços ao objetivo perseguido; saber, isto é, a atitude profissional que permite bem escolher e bem dirigir as operações agrícolas".

Na França, como nos demais países do continente, as novas práticas agrícolas só irão se generalizar no século XIX, apesar das crises alimentares que continuam a ocorrer ${ }^{28}$. Ao longo do século XVIII o esforço contínuo realizado por agricultores inovadores ("yeomen" ou senhores de terra) para reestruturar a grande propriedade e the conferir uma gestão moderna "à inglesa", se chocou com uma forte resistência do mundo camponês, dando origem a revoltas cujo caráter anti-capitalista parece bem estabelecido, apesar da linguagem anti-feudal ainda empregada ${ }^{29}$. Os mais pobres, trabalhadores sem terra e pequenos produtores, se revoltam contra práticas agrícolas que lhes ameaçam o modo de vida. É preciso ter em conta que, apesar da degradação das relações feudais, ainda subsistem alguns dos direitos básicos do servo de gleba ${ }^{30}$. Bloch (1976) assinala, inclusive, casos de aliança entre servos contra os arrendatários capitalistas na luta para preservar os direitos sobre as terras comunais. "A força da propriedade camponesa, nascida do costume, num tempo quando a terra era mais abundante que o homem, consolidada em seguida pela jurisdição real, não havia somente moderado as conquistas do capitalismo rural. Ela freiava também a revolução agrícola e, ao retardá-la, ela impedia também que esta, no seu ímpeto, atingisse muito

Sigaut (1978, p. 37), observa que durante tocla segunda metade do século XVIII até a revolução em 1789, a questão da produção e comércio de grâos era o tema mais polêmico, que despertava maiores paixốes na opiniâo pública. Cacha autorichade local procurava impedir a safcla de grâos ao menor sinal de carestia. E, como sempre, as cidades, melhor organizadas, eram geralmente vencedoras nesta competiçâo com o campo. Para o poder real o abastecimento de Paris era prioritário por causa do risco de revol ta em caso de falta de grãos.

29 Durante o século XVIl as revoltas camponesas eram sobretudo anti-fiscais e ocorriam sobretudo no oeste da França. No século XVIII elas se tornam claramente anti-senhoriais e se deslocam para o norte, nas principais regiōes produtoras de cereais, onde o capitalismo agrário era mais ativo. Portanto, a linguagem é anti-feuchal, mas o móvel sâo as transformações de caráter capitalista que ar estã̃o ocorrendo. Ver Braudel, F. (1979, tomo, p. 258).

30 Principalmente o direito ao uso dos recursos comunitários, como as florestas, os campos naturais e a terra em "pousio" e o direito à planagen, após a colheita. 
ROMEIRO, Ademar Ribeiro. Revolução industrial e mudança tecnológica na agricultura européia.

cruelmente as massas rurais. Os camponeses que não possuiam terra ou a tinham perdido, eram as inevitáveis vítimas das transformações da técnica ou da economia". Bloch, M. (1976, p. 237).

Por outro lado, as vastas regióes onde subsiste um campesinato livre, que representa cerca de metade da propriedade fundiária francesa, permanecem tranqüilas neste final de Antigo Regime, apegadas às antigas práticas agrícolas. Olivier de Serres (1600), embora tenha sido um dos grandes incentivadores do progresso técnico na agricultura em sua época, assim se expressa sobre o que ele considera uma atitude, correta prudência dos camponeses: "... não é necessário prescrever certos conselhos e regras de cultivo de cereais... basta que se siga os costumes, que desde há muito passam de pai para filho, devido ao medo de perda que toda mutação traz consigo. É isto que fez o oráculo proferir a Catão, não mude nunca de arado, suspeite toda novidade. Por isto, aqueles que inventaram novos arados provocam apenas admiração, face a majestade do Antigo modo de trabalhar a terra, da qual se deve desviar o menos possível e após grandes considerações". Serres, O. $(1600$, p. 82).

O resultado desta resistência foi que com a queda num só golpe do Antigo Regime, na noite de 4 de agosto de 1789, a terra na França ficou irremediavelmente retalhada entre camponeses e burgueses; a concentração capitalista da propriedade apenas havia começado, o que obviamente dificulta a difusão das novas práticas agrícolas. $O$ código de Napoleão vai agravar este parcelamento da propriedade fundiária com o direito de herança, enquanto na Inglaterra prevaleceu o direito do primogênito ${ }^{31}$.

\section{Os limites do novo sistema de cultura}

Nós examinamos até aqui os fatores que retardaram, bem como, aqueles que estimularam a difusão do novo sistema de cultura, o sistema de rotação de tipo Norfolk ${ }^{32}$. A principal força de difusão era a perspectiva de lucro aberta pela expansão do mercado urbano-industrial. É interessante

31 Braudel (1979, tomo 3, p. 487) se pergunta se a Inglaterra foi preservada do retalhamento da propriedade devido apenas ao direito do primogênito ou pelo próprio avanço precoce da agricultura capitalista.

32 Norfolk é o nome do condado inglês por onde o novo sistema de cultura se difundiu na Inglaterra. Se trata de uma regiåo de solos arenosos pobres, mas que apresentava a vantagem de ser fácil de trabalhar (solos leves). Quanto à baixa fertilidade, esta foi superada pelo próprio sistema de cultura que, como vimos, enriquecia progressivamente o solo. 
notar, entretanto, que entre os obstáculos à difusão do novo sistema já se encontravam as forças econômicas responsáveis pela sua substituição por outro sistema de cultura. A natureza destas forças aparece claramente quando, na segunda metade do século XIX, Heuzé (1862, p. 14) afirmava que para ter sucesso já não bastava seguir corretamente as rotações recomendadas pelos agrônomos, mas que era necessário também levar em conta as "circunstâncias econômicas". Em outras palavras, o que é recomendável do ponto de vista agronômico pode não sê-lo do ponto de vista econômico. Braudel (1979, tomo 1, p. 93) assinala que as regiões das grandes culturas de cereais na França estavam entre as que apresentavam maiores resistências à introdução do novo sistema de cultura, apesar de se tratar de regiões de grandes propriedades capitalistas.

\subsection{A lógica da monocultura}

Estas regiões de solos profundos e férteis haviam desde longa data se especializado na produção de cereais, especialmente o trigo, enquanto que as regiōes menos favoráveis se dedicavam sobretudo à criação animal. A evolução favorável dos preços dos produtos animais havia levado estas grandes propriedades a uma certa diversificação da produção, mas sempre mantendo o viés cerealista. Como vimos, no novo sistema a área consagrada à produção de cereais correspondia a apenas $50 \%$ da área total, o restante sendo cultivado com forrageiras. Esta redução da área cultivada com trigo encontrava forte resistência entre estes agricultores na medida em que os preços deste cereal, apesar de flutuarem, eram sempre atrativos. Ou seja, para estes agricultores era mais lucrativo cultivar apenas o produto melhor cotado no mercado. A rotação de culturas que impunha o novo sistema de cultura, embora apresentasse inúmeras vantagens do ponto de vista agronômico, era vista como uma restrição por agricultores cujas terras eram boas para o cultivo do trigo, "o cereal mais precioso".

As reticências destes grandes agricultores com relação ao novo sistema acabam por se refletir na posição dos divulgadores e entusiastas do "sistema inglês" na França. Por exemplo, a partir da segunda edição de seu manual, Mathiew de Domsbale (1846, p. 542) acrescenta uma revisão crítica dos princípios do novo sistema expostos vinte e cinco anos antes, na qual ele pondera que certas regras agronômicas da rotação de culturas, como a proibição de dois cereais sucessivos, haviam sido estabelecidas de modo excessivamente rígido. Aqueles que se submetiam a ela ficavam impedidos de 
ROMEIRO, Ademar Ribeiro. Revoluçẩo inclustrial e mudança tecnológica na agricultura européia.

obter "colheitas muito lucrativas que não reduzem a fertilidade do solo se os cultivos forem realizados judiciosamente. Nos antigos sistemas de cultura se abusava dos cereais, e este abuso era nocivo; mas também é um abuso querer reduzir excessivamente a extensão das terras consagradas a estas colheitas que, na maioria dos casos, proporciona aos agricultores o produto líquido mais garantido".

Em consequência, ele propõe a realização de algumas modificações no sistema de rotação de modo a aumentar a superfície consagrada ao cultivo de cereais. Cerca de vinte anos mais tarde, outro dos grandes divulgadores franceses do sistema inglês vai reconhecer, numa espécic de auto-crítica, que "é sem razão que se recrimina hoje em dia os agricultores que seguem o sistema bienal dos antigos ou o sistema trienal recomendado por Carlos Magno, obtendo com estes sistemas colheitas muito satisfatórias com relação ao valor locativo da terra e ao quociente de capital empregado... Não seria excessivo criticar severamente os escritores que, a priori, consideram o sistema trienal como uma agricultura rotineira. Este sistema judiciosamente aplicado e apoiado por uma extensão suficiente de pastagens, tem permitido, e permitirá, ainda por longo tempo, em várias regiões, se fazer dinheiro com a agricultura". Heuzé, G. (1862, p. 87). Estes agricultores praticavam o que Heuzé (1862) classifica de cultura "livre ou variável"; eles mudavam de cultura ao sabor das flutuações dos preços de mercado, procurando maximizar os lucros produzindo apenas o produto que apresenta a melhor perspectiva de rentabilidade. No entanto, no século XIX a monocultura total, sobretudo de cereais, era impossível de ser praticada devido ao desgaste que provocava no solo. Somente solos excepcionais a suportavam, aqueles que tinham uma excelente estrutura física e grande fertilidade natural (ou próximos de fontes urbanas de fertilizantes orgânicos). Este era o caso dos famosos chernozen ucranianos e de algumas regiões da França onde se cultivava "cereais sobre cereais há séculos". Os problemas de infestações de pragas nestas regiões de monocultura eram mais ou menos solucionados com o cultivo, de tempos em tempos, de pastagens no lugar dos cereais. Nas demais regiões de terras boas, mas não excepcionais, a falta de fertilizantes e a relativa fragilidade dos solos obrigavam os agricultores a criar um mínimo de animais.

Os rendimentos em cereais assim obtidos eram razoáveis, embora inferiores aos que poderiam ser obtidos com o sistema de rotação de tipo Norfolk, que apresentava ainda a vantagem de uma maior produção animal. Além disto, é preciso considerar que este era também bastante flexível no que diz respeito às flutuações do mercado, permitindo a concepção de seqüências 
variadas de culturas ${ }^{33}$. Finalmente, cabe considerar o menor risco de perdas que o novo sistema oferecia, seja aquelas provocadas por doenças, ou aquelas decorrentes de flutuações muito violentas do preço de algum produto. No entanto, apesar de obterem uma produção total de cereais equivalente à que poderia ser obtida com o novo sistema e correr um risco maior de perda, os agricultores capitalistas nas regióes de boas terras resistiam a mudar de sistema de produção. Apesar de tudo, a perspectiva de lucro com a monocultura era maior devido às vantagens que oferecia do ponto de vista do controle do processo de trabalho e das rendas diferenciais que podiam ser obtidas.

\subsubsection{O problema do controle e organização do processo de trabalho}

Desde o final do século XVIII a falta de "braços" se fazia sentir. As exortações contra o êxodo rural $^{34}$ se multiplicam, embora este seja um fenômeno localizado, pois, como assinala Dovring (1965), o número absoluto da população rural na Europa só começa a declinar no final do século XIX. As regiões onde o problema se faz sentir são aquelas das grandes culturas, as quais dependiam do trabalho de trabalhadores volantes mal pagos e, por isso mesmo, mais suscetíveis à atração exercidas pelas cidades. A questão é saber agora em que medida este fato dificultava a difusão do novo sistema de cultura, favorecendo a prática da monocultura. À primeira vista isto se deve ao simples fato de que o novo sistema exigia maior quantidade de trabalho, o que implicava problemas de recrutamento de trabalhadores nestas regiões de grandes propriedades. Isto está de acordo, por exemplo, com a hipótese de Dovring (1965, p. 638), segundo a qual "o sucesso das novas práticas (mixed farming) na Europa dependia em grande medida da persistência de uma alta densidade de mão-de-obra nos campos".

33 Autores como Laurent (1976, p. 678) apontam como uma das vantagens do novo sistema justamente a flexibilidade de concepção de sequiências de rotaçóes de acordo com as necessidades de mercado. No entanto, as vantagens da monocultura de cereais tornavam, como veremos, desnecessário esta maior flexibilidade do sistema.

34 "Há queixas em todas as províncias de que os braços faltam, que as artes, de primeira necessidade ou de luxo, atraem os habitantes dos campos para as cidades: a quantidade surpreendente de camponeses que af se atiram, aumentando a classe mais desprezível de tocks os homens, a dos lacaios, acabam por despovó-los... É uma raça perdida: tendo uma vez bebido a taça envenenada das grandes cidades, eles esquecem o lugar que os viu nascer". LAbbé Rosier, citado por Festy, O. (1950, p. 20). 
ROMEIRO, Ademar Ribeiro. Revolução industrial e mudança tecnolరggica na agricultura européia.

No entanto, o problema maior não se devia à maior quantidade de mão-de-obra exigida pelo novo sistema. Como vimos, a operação agrícola que exigia maior quantidade de trabalho em relação ao antigo sistema era 0 controle de ervas daninhas durante todo o período de crescimento das culturas de raízes forrageiras ou plantas industriais que abriam o sistema de rotação; operação para a qual se contava há mais de um século com a carpideira mecânica inventada por Jethro Tull. $O$ problema maior se devia na verdade à qualidade da máo-de-obra exigida. O novo sistema era mais complexo, exigindo uma coordenação mais cuidadosa dos trabalhos agrícolas. Para a propriedade camponesa baseada no trabalho familiar isto não era problema. Mas quando se trata de uma grande propriedade capitalista, que depende de mão-de-obra assalariada, o novo sistema traz problemas praticamente insolúveis de controle e organização do processo de trabalho.

Na agricultura, devido as suas especificidades naturais, não é possível, como na indústria, dividir e parcelizar o processo de trabalho de modo a simplificar o trabalho executado por cada trabalhador e com isto facilitar o seu controle pela gerencia capitalista. A dispersão do campo de trabalho, o caráter sequencial das operações agrícolas, uma máquina produtiva composta de seres vivos, tudo isto impede o controle adequado do processo de trabalho, ficando com o trabalhador a responsabilidade maior pela qualidade do trabalho executado.

A preocupação com a qualidade da mão-de-obra aparece clara num relatório sobre a Lei da Pobreza de 1834 na Inglaterra. Neste os fazendeiros são exortados a empregar mais mão-de-obra para reduzir a pobreza e evitar a "desmoralização" da força de trabalho. Mas os trabalhadores deviam ser diligentes e hábeis, qualidades estas que somente poderiam ser estimuladas se o salário fosse estipulado em função dos méritos e potencialidades de cada um é não em função do tamanho das famílias, como era estipulado pela lei com relação aos trabalhadores que acabam vivendo da caridade pública nas paróquias. O relatório explicita que o zelo e a habilidade eram vistos como qualidades indispensáveis, na medida em que era muito difícil para o fazendeiro inspecionar pessoalmente os trabalhadores dispersos na propriedade; ele não conseguiria evitar as depredações e as perdas. Na maioria das tarefas agrícolas a correção do trabalho realizado depende quase que inteiramente da consciência profissional do trabalhador; somente os resultados de uma pequena parte do trabalho realizado seria suscetível de avaliação imediata, podendo, deste modo, serem pagos por peça ${ }^{35}$ tal como na indústria. 
Nas regiões de grande cultura na França a base de mão-de-obra familiar e de "agregados" de confiança, ideal para a realização de um trabalho mais cuidadoso e correto, era insuficiente face a extensão das propriedades, o que as obrigava a contratar trabalhadores assalariados. Havia, portanto, uma preocupação constante não somente em reduzir ao máximo a folha de pagamentos através da mecanização, como também de simplificar o processo de trabalho de modo a tornar possível o emprego de mão-de-obra barata $\mathrm{e}$ pouco qualificada: "Considerando a perfeição do trabalho como uma coisa secundária, tendo necessidade de lutar contra a raridade de braços e, além do mais, tendo interesse em produzir o mais economicamente possível, ela emprega ac máximo os tarefeiros e as máquinas destinadas a substituir uma mão-de-obra custosa. Esta maneira de agir simplifica consideravelmente o andamento da empresa, mas ela obriga o fazendeiro a uma vigilância constante". Heuzé, G. (1862, p. 102).

Como se vê, a simplificação do sistema de cultura torna viável a utilização de mão-de-obra assalariada, mas não elimina a necessidade de uma "vigilância constante" por parte do proprietário ${ }^{36}$. Este é um problema que surge desde a baixa Idade Média, quando se assiste a aparição dos primeiros "kulaks", como resultado do processo de diferenciaçăo do campesinato, e da entrada em cena dos primeiros senhores feudais que se transformam em proprietários capitalistas ao assumir diretamente o controle da produção. Como dizia Olivier de Serres (1600) "o mestre desde o despertar/ na fazenda é um sol" (Le maistre dès son resveil / Au mesnage est un soleil). Trata-se de um problema inevitável quando as relações capitalistas impessoais substituem as relações de engajamento e compromisso pessoais características da sociedade feudal. No setor industrial este problema foi em grande medida solucionado, como se sabe, por uma nova forma de organização do processo produtivo na qual a iniciativa e a responsabilidade pela qualidade do trabalho são transferidas para o controle da gerência capitalista. $\mathrm{Na}$ agricultura, por suas especificidades naturais, não é possível organizar o processo de trabalho de modo análogo. Enquanto a mecanização não eliminar totalmente a neces-

36 "De qualquer modo, se o trabalho executado por tarefeiros é sempre mais barato do que aquele executado por trabalhadores residentes, no entanto ele impöe uma supervisáo mais incessante. Se o trabalhador doméstico trabalha executa mal uma operação é por falta de conbecimento; nåo acontece a mesma coisa no caso das operações executadas pelos tarefeiros; se esta execuçăo dei$x a$ a desejar $e ́$ porque o trabalhador agiu de modo a operar rapidamente e ganhar mais por dia de trabalho". Heuzé, G. (1862, p. 131). 
ROMEIRO, Ademar Ribeiro. Revolução industrial e mudança tecnológica na agricultura européia.

sidade de trabalho assalariado, o produtor agrícola capitalista terá sempre sérios problemas de controle e supervisão do processo de trabalho ${ }^{37}$.

\subsubsection{As rendas diferenciais}

Para os agricultores melhor colocados em termos de terras, adotar as novas práticas implica a perda da renda diferencial que obtém com a prática da monocultura. Como vimos, o novo sistema de cultura era também chamado de cultura melhorada ou progressiva, por causa da restauração e melhora dos solos que promovia. Seu efeito benéfico era particularmente significativo sobre os solos arenosos leves, considerados até então como as piores terras para o cultivo de cereais. A ponto da difusão das novas práticas na Inglaterra no século XVIII ter praticamente invertido a carta de aptidão agrícola do país $^{38}$. O aperfeiçoamento no século XIX dos instrumentos para trabalhar solos argilosos pesados e os novos métodos de drenagem, vão eliminar a vantagem que o novo sistema de cultura passara a conferir aos solos arenosos leves, mas sem recuperar a antiga vantagem dos primeiros vis-a-vis aos segundos.

Em outras palavras, o novo sistema de cultura reduz as diferenças de qualidade entre os diversos tipos de solo o que, por conseguinte, diminui as rendas diferenciais auferidas pelos agricultores melhor colocados. A monocultura, especialmente a de cereais, ao contrário, exacerba as diferenças de qualidade entre os solos. Os rendimentos que os agricultores das regióes de grande cultura na França podiam obter com a monocultura de cereais baseada no antigo sistema de "pousio" feudal eram muito superiores, tendendo a aumentar, àqueles que poderiam ser obtidos com o mesmo método em solos arenosos leves. Com o novo sistema, ao contrário, as diferenças de rendimento tendiam a desaparecer.

37 Dovring (1967, p. 168) observa que os grandes proprietários frẹüentemente forçaram a introduçâo da monocultura tanto por raző̉es de supervisîo como de mercado.

38 Leonce Lavergne em seu relatório de viagem sobre a economia rural da Inglaterra, Escócia e Irlanda (The Rural Economy of England, Scotland and Ireland, 1855), assinala que a regiâo de Lothians na Escocia havia se tornado famosa por seus cereais. Anteriormente, o solo desta região era conhecido por sua incapacidade de suportar até mesmo os cereais menos exigentes e resistentes a solos pobres e pouco profuncos. Com o sistema de rotaçảo de tipo Norfolk se passou a obter rendimentos entre 95 e 45 bushels de trigo por acre. Ver também os "Discurssos" de Sir Richard Weston (A Discours of Husbandrie used in Brabant and Flandres, 1652), sobre a conversão das terras arenosas e pobres em solos extremainente produtivos. In Mingay, G.E. (1977). 
A falta de fertilizantes vai acabar por impor modificações na prática da monocultura, obrigando o agricultor a cultivar uma certa área com culturas forrageiras, embora mantendo o viéz cerealeiro ${ }^{39}$. Nestas regiões a criação animal será sempre considerada como um "mal necessário", do qual elas só se verão livres com a chegada dos fertilizantes químicos, dos pesticidas e dos meios mecânicos possantes de reestruturação do solo. A partir de então será possível praticar a monocultura total e recuperar, assim, as rendas diferenciais obtidas anteriormente. Em síntese, a Revolução Industrial vai tornar possível o abandono das práticas agrícolas cuja difusão ela própria havia suscitado e sem a qual a expansão urbana-industrial européia teria sido bloqueada.

\section{BIBLIOGRAFIA}

BEAUMONT, O. and Higgs, J.W.Y. (1958). Agriculture: Farm Implements, in A History of Technology, ed. by C. Singer, E.J.Holmyard, A.R. Hall and T.I. Williams, vol. IV, Oxford at the Clarendon Press.

BLOCH, M. (1976). Les Caractères Originaux de l'Histoire Rurale Française, Librairie Armand Collin, Paris.

BLOCH, M. (1978). L'Individualisme Agraire dans la France du XVII Siecle, Librairie Armand Collin, Paris.

BOSERUP, E. (1970). Evolution Agraire et Pression Démographique, Flammarion, Paris.

BRAUDEL, F. (1979). Civilisation Matérielle, Économie et Capitalisme, XVème-XVIIème Siccles, 3 Tomes, Librairie Armande Collin, Paris.

DEMOLON, A. (1946) . L'Evolution Scientifique de l'Agriculture Française, Flammarion Ed., Paris.

DOVRING, F. (1965). The Transformation of European Agriculture, in The Industrial Revolution and After: Income, Population and Technological Change (II), The Cambridge Economic History, ed. by H.J. Habakkuk and M. Postan, Cambridge at the University Press.

DUHAMEL DU MONCEAU, H.L. (1753). Traite de la Culture de Terres Suivant les Principes de Mr. Tull, H.L.Guevin et L.F. Delatour édit., Paris.

39 Alguns destes agricultores, cujas terras eram muito boas conseguiram resistir à mudança de sistema, pois Zolla (1913) observa que no primeiro decênio do século vinte o sistema de "pousio" era ainda praticado. 
ROMEIRO, Ademar Ribeiro. Revolução industrial e mudança tecnologgica na agricultura européia.

FESTY, O. (1950). L'Agriculture pendant la Revolution Française - L'Utilisation des Jachères - 1789/1795, Librairie Marcel Rivière et Cie., Paris.

FUSSEL, G.E. (1958). Agriculture: Techniques of Farming, in A History of Technology, ed. by C. Singer, E.J. Holmyard, A.R. Hall and T.I. Williams, vol IV, Oxford at the Clarendon Press.

GANSHOF, F.L. (1942). Medieval Agrarian Society in Its Prime, in The Agrarian Life in the midle Ages, The Cambridge Economic History, ed. by J.H.Claphan and E. Power, Cambridge at the University Press.

HEUZÉ, G. (1862). Les Assolements et les Systemes de Culture, Hachette, Paris.

HOBSBAWN, E. (1975). A Crise Geral da Economia Européia no Século XVII, in Capitalismo, Transição, Org. Theo A. Santiago, ed. Eldorado, Rio de Janeiro.

KULA, W. (1979). Teoria Economica do Sistema Feudal, Ed. Presença, Lisboa.

LAURENT, R. (1976). L'Utilisation du Sol: la Rénovation des Méthodes de Culture, in Histoire Economique et Sociale de la France, Tome III, vol. II, Presses Universitaires de la France, Paris.

LECOUTEUX, E. (1855). Principes Économiques de la Culture Améliorante, Librairie Agricole de la Maison Rustique, Paris.

LECOUTEUX, E. (1881). Principes de la Culture Améliorante, Librairie Agricole de la Maison Rustique, Paris.

LECOUTEUX, E. (1883). Le Ble. Sa Culture Intensive et Extensive. Commerce-prix de revient, tarifs et legislation des céréales, Librairie Agricole de la Maison Rustique, Paris.

LE ROY LADURIE, E. (1977). Les Masses profondes: la paysannerie, in Histoire Economique et Sociale de la France, dir. par F. Braudel et E. Labrousse, tome III, vol. II, Presses Univ. de France, Paris.

MATHIEU DE DOMBASLE, C.-J.-A. (1846). Calendrier du Bon Cultivateur ou Manuel de l'Agriculteur Practicien, Paris.

MAZOYER, M. (1977). Evolution et Differenciation des Systèmes Agricoles D'Exploitation de la Nature, in Le Hommes el Leurs Sols, $\mathrm{n}^{2}$ special du Journal d'Agriculture Tropicale et de Botanique Appliquée, vol 24, n. 2/3, Avr./Sept.

MINGAY, G.E. (1977). The Agricultural Revolution. Changes in Agriculture 1650-1880, Adam and Charles Black, London.

NORTH, D.C. and THOMAS, R.P. (1973). The Rise of the Western World. A New Economic History, Cambridge at the University Press.

SERRES, O. (1600)Le Theatre d'Agriculture et Mesnage des Champs. La Maison Rustique, Paris.

SIGAUT, F. (1978). Les Réserves de Grains à Long Terme. Techniques de Conservation et Fonctions Sociales Dans l'Histoire, ed. de la Maison des Sciences de l'Homme et Publications de l'Université de Lille III.

SLICHER VAN BATH, B.H. (1969). Eighteenth Century Agriculture on the Continent of Europe: Evolution or Revolution?, in Agricultural History, v. 43, n. 1, January.

TAKAHASHI, H.K. (1972). Uma Contribuição para a Discussão, in Do Feudalismo ao Capitalismo, Publicações Don Quixote, Lisboa.

TIMMER, P.C. (1969). The Turnip, The New' Husbandrie, and The English Agricultural Revolution, in The Quaterly Journal of Economics, vol. LXXXIII, August. 
R. História, Sẫo Paulo, n. 123-124, p. 5-33, ago./jul., 1990/1991.

TULL, J. (1733). The Horse-Hoing Husbandry, in Readings in the History of American Agriculture, ed. by W. Rasmussen, University of Illinois Press, Urbana, 1960 USHER, A.P. (1913). The History of the Grain Trade in France, 1400 - 1710, Harvard University Press, Cambridge.

WHITE, L. (1962). Medieval Technology and Social Change, Oxford at the Clarendon Press.

ZOLLA, D. (1913). L'Agriculture Moderne, Flammarion Ed., Paris.

ABSTRACT - This text approaches questions relative to the transferences in agricultural practices taking place in $\mathrm{XVIII}^{\text {th }}$ and $\mathrm{XIX}^{\text {th }}$ century Europe. Focusing on England, the author examines questions relative to the demographic distribution between the urban and rural areas.

The implantation of new instruments and the ack of fertilizers are aspects that are analysed in this text. The transformations coherence draws a parallel to the Industrial Revolution. 